\title{
INTERNATIONAL PERSPECTIVES ON TRANSPORTATION AND URBAN FORM INTEGRATION
}

\author{
C.B. SCHOEMAN \\ Northwest University, Potchefstroom Campus, Republic of South Africa.
}

\begin{abstract}
The debate of transportation and urban form integration has been reported on by several authors since the early 1960s. However, in 2015, the challenges were much more dynamic, diverse and complex. From research undertaken it is evident that the approach to integration is determined by the disciplinary focus of the researcher and/or practitioner and the research methodology used and is closely related to the conditions (case study research) prevailing within a specific spatial system (countries).

This article is an endeavour to assess and evaluate different integration approaches and outcomes deduced from existing research and case studies by critically evaluating its point of departure, approaches and practices applied in various spatial systems (international perspectives) and more specifically by the disciplines involved in this discourse. It includes the theoretical founding and related empirical research considerations where this phenomenon is an important focus in transportation planning and spatial integration in promoting and attaining sustainable development and urban resilience.

The process is, however, dependent on the relationship between the principles underpinning this research theme. There is a co-dependence between transportation and urban form. This co-dependency is, however, being complicated by decision making and the environmental reality that needs to be factored into this reality.

The outcome of the article will focus on isolating international guiding principles from an integration perspective in promoting sustainable development and resilience in spatial systems. It will include strategic directions and decision-making processes inclusive of environmental considerations, optimizing urban form and land-use planning (patterns), related impacts, accessibility, modal integration, transportation network development and energy and pollution influences, effects and implications. The need for trans-disciplinary practices and application of strategic approaches in integrating planning, development and operational-level interfaces within urban spatial systems will be demonstrated.

The use and application of modelling and simulation techniques are becoming more important as an instrument to guide and measure the attainment of higher levels of integration and sustainability. Transportation and spatial development integration paradigms are dependent on the application of technology that is measureable for all spatial development scenarios in terms of effects, progress, implications and pre-conditions to enhance integration.
\end{abstract}

Keywords: integration, land uses, network planning, spatial systems planning, transportation, urban form.

\section{INTRODUCTION}

The debate of transportation and urban form integration has been reported on by several authors since the early 1960s. Central to this theme is the interface between transport system and urban form development. Schoeman [1-3] has been addressing the issues related to transportation and urban development in various conference papers presented at urban transport conferences of Wessex Institute of Technology (WIT) since 2004. The focus that is representative of a developing spatial system was dealt with from a South African perspective. This research focus has now broadened to the theme of international perspectives on transportation and urban form from a theoretical and empirical perspective. Value is thus added in the sense that the article now directs the research on transportation and urban form integration as it is experienced internationally. 
In 2015 the author edited a book on land use management and transportation planning focusing on specific themes fundamental to transportation and urban form integration [4]. The content of this article will thus broaden the debate to the realities existing in developed spatial systems and the lessons it holds for developing spatial systems (previous research focuses).

Urban form refers to the structure of spatial systems (rural, transition zones, towns, cities, metropolitan areas and regions). Spatial systems are integrated through connectivity inclusive of the movement of people, goods, services and information. This article thus focuses on the international perspectives of urban form integration inclusive of strategic management, sustainability and resilience as fundamental system-influencing components.

From a study of applicable regional and urban planning theory, the deduction can be made that transportation systems guide connectivity, development and growth within all spatial systems. Dawkins [5] gave a comprehensive overview of regional development theories that in terms of the theme of this article forms the conceptual background to the role of transportation and urban form in terms of integration. From an assessment of these theories, transportation forms the core consideration underpinning all regional and urban development and growth theories.

The American urban form inclusive of spaces, places and boundaries that define city life has been evolving since the first settlements during the colonial days. This process is reflected in the changing patterns of houses, buildings, streets, parks, pipes and wires, wharves, railroads, highways and airports inclusive of changing patterns of the social, political and economic processes that shape the city and thus urban form. Warner and Whittemore [6] and Larkham [7] compiled a study of urban form in Great Britain. Their research came to the same conclusion (as summarized by Larkham [7]) that 'Urban form is defined unusually widely and many disparate strands have an influence upon that definition as currently conceived, including the considerations of agents and agency in urban change (p. 114).'

A strong relationship is emerging between population growth and urban size, which has important implications for how New Zealanders think about their cities [8]. The core findings of the report state that the first implication is that existing urban areas are attracting young people and migrants, who may have needs that vary from the general population. The second implication deduced is that 'scale matters'; the bigger a city is now, the more likely it is to grow in the future. For this reason the report finds that cities and towns that are important today are likely to remain important in the future, hence a relatively long-term view of urban development should be encouraged.

Transportation and urban form in Chinese cities are dealt with by Kenworthy and Hu in their paper 'An International Comparative and Policy Perspective with Implications for Sustainable Urban Transport in China' [9]. It is thus clear that the topic of transportation and urban form is a phenomenon researched internationally. The study of these international perspectives clearly illustrates specific common approaches, forces and challenges guiding integration.

Muller [10] points that the movement of people, goods and information within local metropolitan area is of critical importance in the functioning of cities. The same applies to regions and related spatial systems within which towns, cities and metropolitan areas function. Rodrique [11] illustrates that transportation and the urban form are directed by forces such as global urbanization, the nature of urban form and evolutions taking place within transportation and urban form and the spatiality of urban transportation, regional transportation and urban structure.

The Organisation for Economic Co-operation and Development International Conference held in Vancouver, Canada, identified the following guiding principles for sustainable transportation: accessibility, people and communities, environmental quality and economic 
viability [12]. Banister and Lichfield [13] also state that transport has a major impact on the spatial and economic development of cities and regions. The attractiveness of particular urban locations depends in part on the relative accessibility, and this in turn depends on the quality and quantity of the transport infrastructure.

The purpose of this article is to provide an overview of all related factors impacting on national, regional, metropolitan, urban and rural spatial system integration in terms of transportation development and urban form. As indicated above there is a co-dependence between this and the need for integration as to enhance system-wide sustainability, resilience and effectiveness. This need can clearly be deduced from the themes and background covered in the introductory remarks.

\section{THE INTERFACE BETWEEN TRANSPORTATION AND URBAN FORM}

The interface between transportation and urban form is well documented and researched in the theory underpinning regional planning, urban development and the development of transport to provide accessibility and integration within regions between urban nodes of different rank and order. Dawkins [5] provides an overview of all theories related to regional planning and urban development. Gist and Fava [14] state that the world's first cities existed since about $3500 \mathrm{BC}$. This clearly demonstrates that urban form existed long before the transportation systems and networks known today were developed. It is thus justified to conclude that transportation developed due to the need to integrate urban and its related urban form manifestations within spatial systems as it is known today.

Mumford in his epic work 'The City in History: Its Origins, Its Transformations and Its Prospects' [15] successfully and in great detail deals with questions such as 'What is the city, How did it come into existence? What processes does it further? What functions does it perform? What purpose does it fulfil?' These questions against the background of the complexities of today's regional and urban realities are indicative of the need to understand the interface between transportation and urban form in an endeavour to promote sustainability and resilience within spatial systems through compact cites as nodes within spatial systems.

Keeble [16, p. 98] states that 'For planning purposes a town may roughly considered to be a settlement which has, or is intended to have, a physical structure sufficiently large and complex to involve problems concerning the location of spatial relationships between land uses and the form of the road system.' For the purposes of this article it includes a relationship within its region (spatial system) as implied by Friedmann $[17,18]$ in terms of spatial growth and development.

The interface between transportation and urban form is also discussed in various standard works dealing with a description of the urban morphology and urban geography and its relationship to urban structure (form) and transportation. This includes bibliographical sources such as The American City: An Urban Geography by Murphy [19]; The Study of Urban Geography by Carter [20]; and The American City: An Urban Geography, second edition by Murphy [21].

Of significance to the theme of this article, the more recent publication of Urban Geography (second edition) by Kaplan et al. [22] is much more related to the forces and impacts influencing the interface and thus the integration between transportation and urban form. In this publication the dynamics and impact of factors such as the changing field of urban geography, background to the development of cities (urban form and structure), metropolitan systems, globalization, telecommunications, technology, social landscapes and related issues such as housing, urban sprawl, urban regeneration, urban segregation, immigration and ethnicity, political landscapes, fragmentation are being dealt with. The significance, however, 
between the original standard sources and the work by Kaplan et al. [22] is the inclusion of the distinction between cities (urban form) in the developed and less developed world.

The question remains how should transportation and urban form and its integration to support sustainability and resilience within spatial systems be defined? Bertraud [23] endeavoured in a general sense to deal with this issue in the paper 'The Spatial Organization of Cities: Deliberate Outcome or Unforeseen Consequence?' Bertraud concludes that urban planners should monitor urban structures to be aware of spatial trends and to understand the limitations imposed by the current structure on policy options. In some cases, it will be possible to influence spatial trends in a limited way.

The researcher points out that Curitiba in Brazil is an example of a city where these conditions were met and where the current city structure is the result of a concerted long range and planning effort [23]. Figure 1 shows the schematic representation of trip patterns within a metropolitan area as deduced by Bertraud [23].

In terms of the focus of this article, transportation and urban form integration consists of inter-transportation and intra-transportation movements focusing on integration of the structure that the supporting spatial system consists of. The integration between transport and urban form is thus a function of both inter- and intra-movements of goods, people, services and information. In order to optimize the need to promote sustainable planning and resilience, interventions on different scales of planning and development are required within all

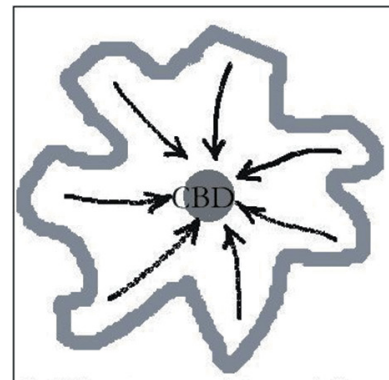

(a) The monocentric model

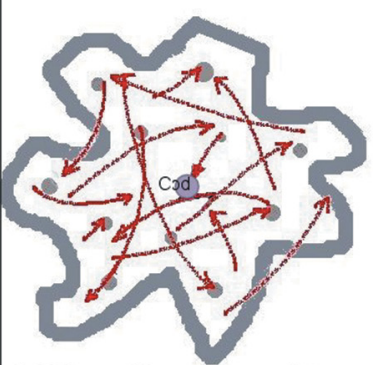

(c) The polycentric model: The random movement version _.... weak links strong inks

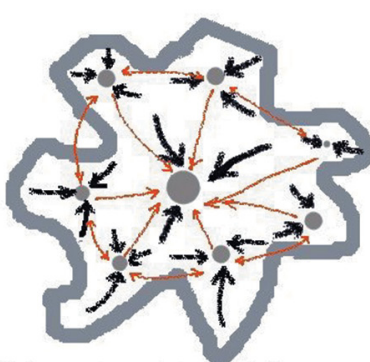

(b) The polycentric model: The urban village version

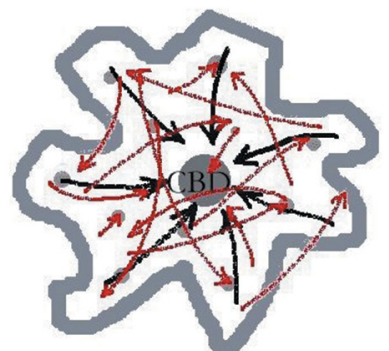

(d) The mono-polycentric model: Simultaneous radial and random movements

Figure 1: Schematic representation of trip patterns within metropolitan areas (Source: Bertraud [23]). 
spatial systems. This articulation includes coordination between different disciplines through processes of strategic planning, lateral thinking and trans-disciplinary practices.

\section{FUNCTIONS, URBAN FORM AND SPATIAL SYSTEMS}

The origin of any spatial system that is urban in nature is dependent on function and location. Aurousseau [24] as far back as 1921 noted that if location is examined in an abstract way, it is evident that function is the driving force in the life of towns and thus the essence of urban form and its supporting spatial system.

Duncan et al. [25] state that what a city does depends closely on where it is (in a spatial system) that function and location seem like the two sides of a coin. Carter [20] notes that the essence of urban character is service delivery for a tributary area related to central place functions after the theory published by Walter Christaller on central places. Carter further states that central place functions of urban areas should be conducted in relation to transportation functions and special functions such as mining, industry, recreation etc.

Functions and urban form (cities) include the following typologies directing development in spatial systems: military, commercial, industrial, mining, transport, fishing, educational, administrative, recreational, tourism and central place functions. In terms of the theme of this article, a certain function may give rise to the development of a town/city within a spatial system that requires transportation linkages to other urban orientated spatial systems and its hinterland. This in itself may transform such an urban orientated spatial system (node) from having a mono-functional character into a multi-functional character. Although this description seems to be very simplistic, urban functions (form) cannot be understood in its role to transportation only without reference to regional planning theory as described in the introduction to this article.

Regional planning theory underpins development within all spatial systems inclusive of regions, metropolitan and urban areas. A summary of the most significant regional development theory was published inter alia by Dawkins [5]; Nijkamp and Abreu [26]; SzajnowskaWysocka [27]; and Capello [28]. One of the most comprehensive works on regional planning and development was published by Friedmann [18]. He points out that most of the theories as included in the aforementioned literature overviews do not explain the systematic interrelations between development and space and he then developed a theory on the development process in its spatial dimension. Knowledge of these regional planning theories is fundamental in understanding the dynamics of spatial planning systems and its relationship to transportation and its supporting systems and components.

\section{APPROACHES TO INTEGRATION OF TRANSPORTATION AND URBAN FORM}

Albrecht et al. [29] and Albrecht [30] point out that in the 1990s a strategic approach to the organization of space at different levels of scale became more prevalent. Albrecht [30, p. 743] concludes that "The "alternative" strategic planning presented in this paper is conceived as a democratic, open, selective, and dynamic process. It produces a vision to frame problems, challenges, and short-term actions within a revised democratic tradition.' Albrecht et al. [29] and Albrecht [30] further point out that the strategic process is underlain by the following factors:

- It involves content and process

- Statics and dynamics

- Constraints and aspirations

- The cognitive and the collective, the planned and the learned 
- The socio-economic and the political

- The public and the private

- The vision and the action

- The local and the global

- Legitimacy and a revised democratic tradition

- Values and facts

- Selectivity and integrativity

- Equality and power

- Long-term and short-term reality

Oleson [31] has taken the debate further to the neo-liberalization of strategic spatial planning. She states that neo-liberalization of strategic planning has manifested as a result of governance reforms aiming to reduce or abolish spatial planning at national and regional scales. This is in stark contrast to the need for strategic planning as to integrate transportation and urban form in order to optimize and enhance service and infrastructure development, delivery, sustainability and resilience. This action is also in contradiction to the application of such planning instruments and approaches as being dealt with in this article and by planning authorities functioning within various disciplines.

Generally planning (inclusive of urban and regional planning, transportation planning and environmental management) entails the consideration of what can and should happen where in spatial systems. It includes the focuses and interaction of different policies and practices across regional space, and sets the role of spaces, places and interaction between professions in a wider context. It goes well beyond 'traditional' statutory planning (inclusive of authorizations) and includes strategic, planning (functional) and operational activities within transportation, spatial planning (urban and rural) and environmental management.

Pinson [32] states that spatial planning includes the notion that encompasses a set of social activities aimed at anticipating, representing and regulating the development of an urban or a regional area/territory. It includes intellectual activities of study and prospective development, social and economic forecasting with more concrete activities such as infrastructure programming, land reservation and land-use regulation. Pinson further concludes that planning operates at different scales: neighbourhood, city or region.

Litman [33, p. 1] points out that 'Planning refers to the process of deciding what to do and how to do it. Planning occurs at many levels, from day-to-day decisions made by individuals and families, to complex decisions made by businesses and governments.'

\section{ROLE OF EDUCATION AND TRAINING IN PROFESSIONS IN SUPPORTING TRANSPORTATION AND URBAN FORM INTEGRATION}

Figure 2 shows the interfaces between fields of education and training for professions involved in the theme of this article. The core relationships between subject themes and disciples are being depicted in terms of its orientation from a planning and development perspective.

These relationships in education, training and professional development are fundamental for the way in which the alignment and interface is being dealt with in practice, workplace and between professional disciplines.

Table 1 shows a classification of the core focuses for planning activities based on international and national norms and principles. The focuses can be grouped as follows: spatial planning; urban planning; policy and strategy formulation; land-use management; involvement in the built environment; land availability; transportation planning; environmental management; 
Core URP focuses

Fields fundamental to URP

Secondary fields supporting URP

Fields related to URP (non-core)

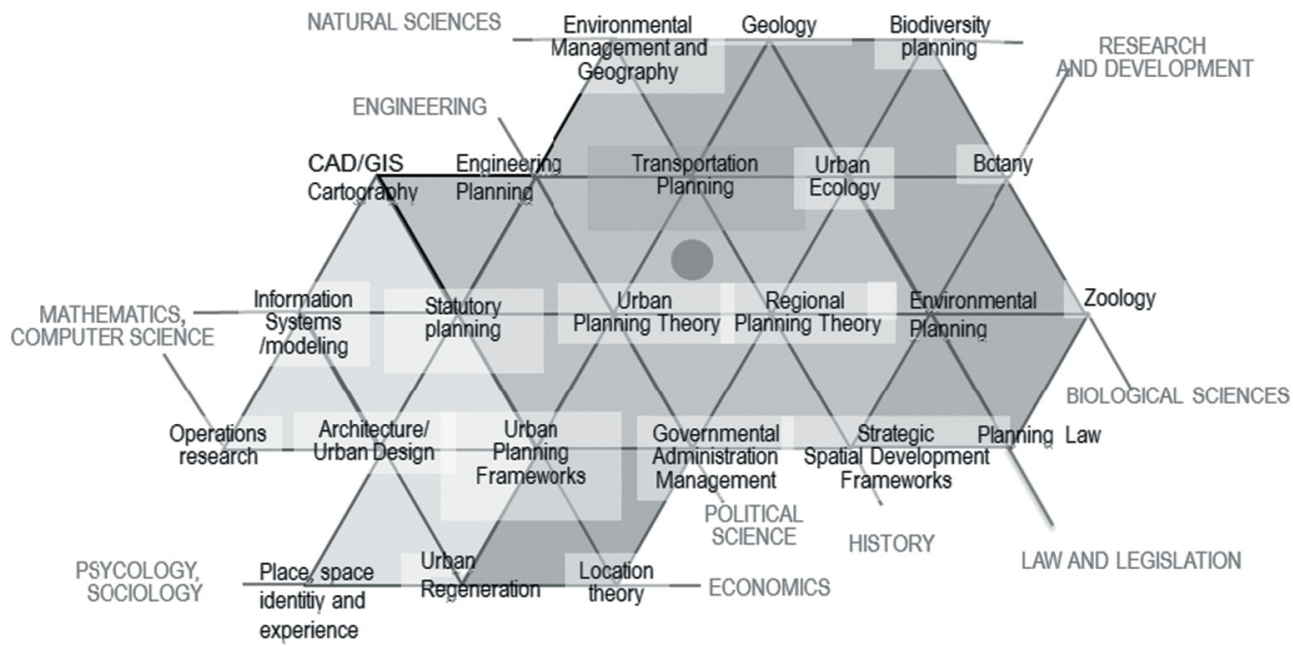

Figure 2: Interfaces in education and training of professions (Source: Schoeman [34]).

impact assessments; authorizations; socio-economic and spatial development; facilitation and communication; human settlement development; rural development; feasibility studies; implementation; project management; and management and analysis based on application of decision support systems.

\section{TRANSPORTATION AND URBAN FORM INTEGRATION FROM A SUSTAINABILITY AND RESILIENCE PERSPECTIVE}

Sustainability within spatial systems refers to the optimization of planning, resources and activities so as to protect the environment through the scientific design, approaches and accountability. This includes transportation, urban form, quality in the utilization of the environment, food production, land and water resources. Sustainability is technology dependent. Resilience consists of the ability of spatial systems to recover from physical, economic, social and natural disasters. Sustainability and resilience within spatial systems are therefore integrated and interdependent. Elmqvist [35] illustrates the relationship between sustainability in Fig. 3 whilst a new view on how it is related is shown in Fig. 4.

As far as alignment and integration from a sustainability need and perspective are concerned, cognizance should be taken of the basic policy and legislative requirements applicable to any country or institutional entity in terms of all spatial systems it consists of. Internationally, alignment and integration between transportation, urban form and environmental management form the focal point in attaining and promoting sustainable 
Table 1: Core planning focuses based on international and national norms and principles.

Core professional planning Domain as interpreted internationally and nationally focus

\section{Part 1}

Spatial planning

Planning systems; practices in regional space; role of places; strategic frameworks; forward planning; scale of regional planning; development in physical environment; spatial plan formulation; impact of migration; regional spatial planning needs; regional corridor and nodal development

Urban planning

Role of places; anticipating development; scale of urban planning; surface and beneath surface development; urban development; urban regeneration and development; urban design; site planning; urban spatial planning needs; neighbourhood development; urban corridor and activity node development; urban renewal

Policy and strategy formulation Interaction of policies; policy interventions; multi-perspective approaches; disaster preparedness plans; input in drafting of policy and legislation

Land-use management

Land-use planning; land-use management and control; regulating development; control of land use; management of change in land use; legal issues related to land use and building codes; legal issues related to environmental regulations

Built environment

Style of buildings; design of public spaces; conservation of historic buildings; development of public spaces and places; location, design and layout of buildings

\section{Part 2}

Land availability

Transportation planning

Environmental management
Land reservation; identification of land for development Innovative forms of transport; accessibility between places of residence, work and amenities; traffic congestion management; air pollution management; transport and land-use models; transportation frameworks

Relationship between built environment; negative impacts on natural environment; natural impacts on communities; protection of natural environments; standard of environmental quality; environmental sustainability; landscape development; legal issues related to environmental management 
Socio-economic and spatial development

Facilitation and communication

Human settlement development

Rural development

Feasibility studies

Implementation

Project management

Management and analysis support systems
Social and economic status quo and forecasting; community regeneration; regional and economic development; rural enterprise; sectoral policies; planning research; technical analysis; smart growth strategies; economic development plans; development of resources; socio economic profiles

Compromise formulation; lead public consultation processes; education, training and capacity building; identification of community needs; community goals and vision compilation; development consultation; public address, meeting and facilitation

Housing development; housing strategies

Community development; area-based planning

Appreciation of spatial complexities; deeper underlying causes; integrated analysis

Infrastructure needs; infrastructure programming; general management; needs prioritization; implementation and enforcement strategies; determination of infrastructure and amenities capacity

Management of programmes for planning and implementation; quality management

Geographic Information System applications and techniques; modelling; systems analysis

Source: Adapted from Schoeman [34].

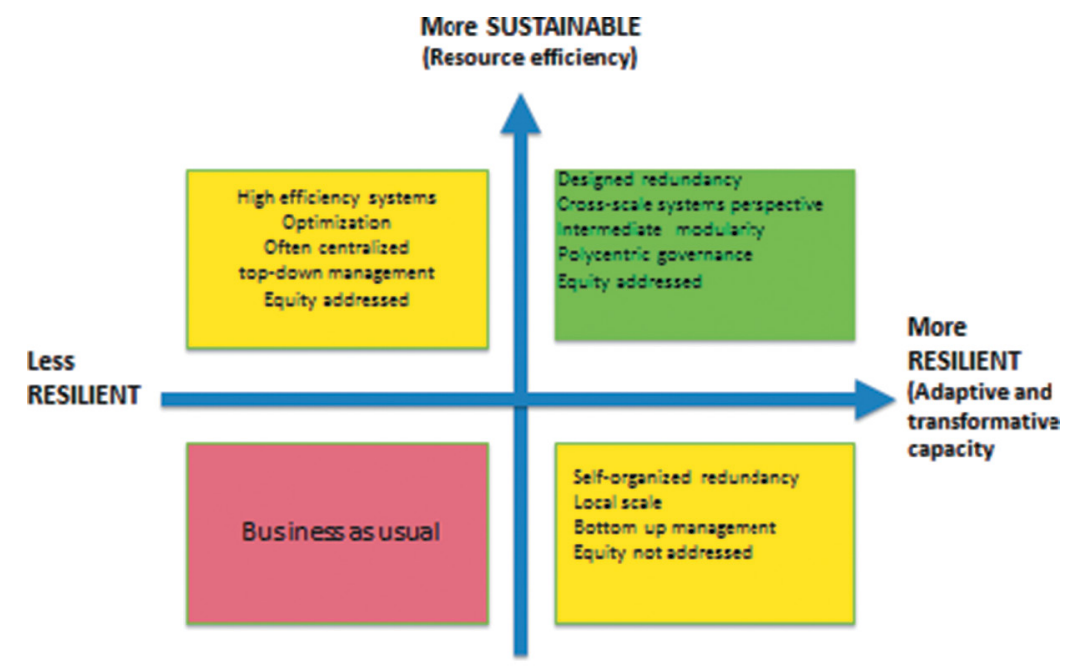

Less SUSTAINABLE

Figure 3: Relationship between sustainability and resilience (Source: Elmqvist [35]). 


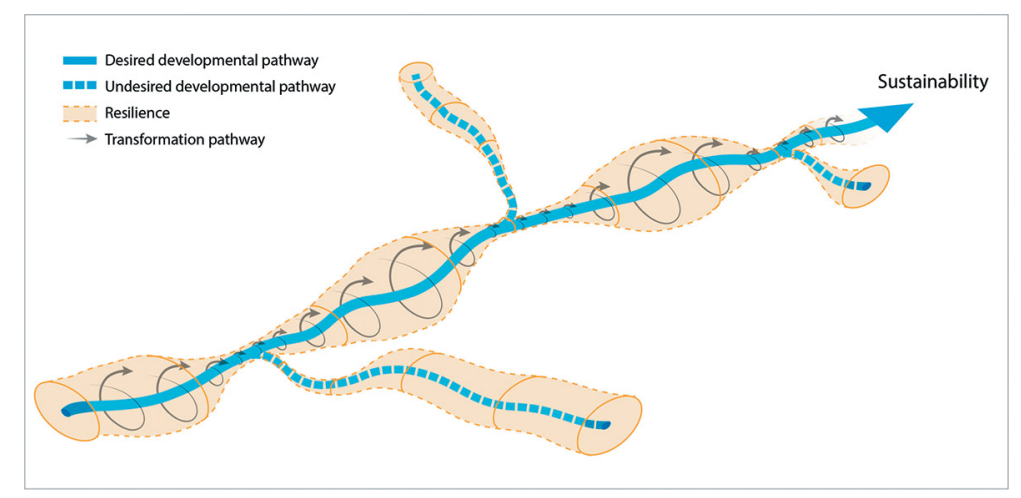

Figure 4: A new way on how sustainability and resilience are related (Source: Elmqvist [35]).

planning and promoting urban and regional resilience, development and delivery (Figs. 3 and 4$)$.

In order to understand the context of this article, one should consider what is implied by the concept of 'alignment'. From a governmental and planning perspective, 'alignment' includes the articulation and optimization of processes contained in goals and objectives (inclusive of communication, involvement, engagement, support and capacity-building activities) to ensure efficient and effective outcomes through optimal application of planning instruments in plan formulation and decision making, as provided for in different policies and legislation across all levels of government in spatial systems.

'Integration', on the other hand, refers to processes and methodological approaches and procedures followed in planning processes through application of specific instruments and/ or planning tools. Alignment and integration are often used interchangeably. To be effective, techniques such as modelling as a tool or instrument should thus be applied to alternative spatial focuses inclusive of urban and rural planning, transportation planning and environmental management.

The dilemma of alignment and integration, or the lack thereof, is also experienced internationally in planning processes in developed and developing countries. The best example from international practices relates to the approach to assess integration in Europe in terms of policy and research. On this topic, Geerlings and Stead [36] state that 'policy' integration should include the following dynamic focuses:

- Vertical integration between different levels of government

- Horizontal integration between sectors or professions in one organization

- Inter-territorial integration between neighbouring authorities or authorities with a shared interest in infrastructure or resources

- Intra-sectoral integration between different sections or professions

Stead et al. [37] identify the following hierarchical foci in dealing with an approach towards integration: co-operation at the lowest level consisting of dialogue and information; co-ordination, coherence and consistency with emphasis on transparency; integration and joinedup policy approaches inclusive of dialogue and avoiding of conflicts. These are supported by inter-organizational coordination; inter-organizational collaboration; intergovernmental management and network management. 


\section{STRATEGIC PLANNING AND MODELLING AS MECHANISMS TO ENHANCE TRANSPORTATION AND URBAN FORM INTEGRATION}

From the arguments above, it is clear that alignment and integration between transportation and urban form to enhance sustainability and resilience within spatial systems (in both developed and developed countries) need a new approach and/or mechanism to promote such goals and objectives. The approaches as formulated by Geerlings and Stead [36]; Stead et al. [37]; Stead and Meijers [38] focus on policy development that is applicable to the theme being dealt with in this article.

Modelling as a mechanism for alignment and integration refers to the endeavour to enhance the interface through representing reality of spatial planning (inclusive of urban and rural planning), transportation planning and environmental management in an abstract way by relating the focuses of planning instruments (plans) to each other with the view to predict impacts and long-term predictions (refer also to Bertraud [23]). It should, however, be noted that modelling per se serves only as a 'tool' or 'instrument' in order to support decision making for complex systems.

Several authors have reported on integrating urban planning and environment in a spatial context. The most valuable contribution to this article relates to the report published by the United Nations Environment Programme (UNEP) in 2013 containing key principles and approaches for cities in the 21st Century [39].

Other publications and approaches more specifically deal with the effects of urban form and/or land use on transportation planning and vice versa [40-42]. Related research themes focused on the development of a framework to assist the integration of environmental, social and economic issues in spatial planning [43]. Research related to the question of spatial planning and environmental assessment [44] also supports the theme as discussed in this article.

However, limited specific research thus far focused on the alignment and interface as discussed in context to the line of argument in transportation and urban form specifically.

The work by McKenna Davis (Editor) [45] in publishing an in-depth case analysis related to green infrastructure is in support of this article. The application of mapping for planning from a sustainability perspective followed by McKenna is fundamental to the theme of this article.

A further example of modelling alignment and integration impacts in support of the theme of this article is contained in the research by Waddell [46] on integrated land use and transportation planning and modelling and the challenges in research and practice. He points out that academic research in integrated land-use planning and transport is on the rise. This statement by implication links closely to the need for the integration of spatial planning, transport and environmental practices as argued in this article. However, alignment and integration consist of much more than to predict outcomes, but includes the task to optimize space and places in terms of planning, development, decision making and delivery. In this the factors of spatial balance, potential realization, impact, continuity, sustainability and resilience are main considerations.

Modelling is basic to decision making and present practices that need to be re-engineered as to support the domains of alignment and integration. This will not only require that the outcome and impacts be modelled for specific development scenarios. The related impacts need to be spatially quantified not only to determine the implications and priorities included in all plans formulated (transportation, land use, urban form and environmental impacts) but also to align spatial consequences, to effect changes to plans in support of integration and to 
address the issue of contradictions, non-alignment of focuses as to enhance sustainability and resilience on a trans-disciplinary level.

Waddell [47] identified the following challenges for integrated modelling:

- Transparency

- Behavioural validity

- Empirical validity

- Ease of use or simplicity

- Computational performance

- Flexibility

- Data availability and quality

- Role of uncertainty

In this application Waddell [47] applies UrbanSim in modelling urban development for land use, transportation and environmental planning. This is possible in developed countries where addressing of the abovementioned challenges could be met. In developing countries only some of the attributes used in UrbanSim can be applied that restricts successful application to assess alignment and integration within such spatial systems.

This implies the development of a more simplified macro-modelling approach to address the challenge of alignment and integration. The methodologies need to be applied to all spatial systems in an integrated fashion to address the dynamics such as interest of different spheres of government, institutions, stakeholders, values, policies, legislation, guidelines and planning within all spatial systems in an integrated approach. Availability of data and other quantifiable information is thus a prerequisite.

\section{LESSONS LEARNED AND CONCLUSIONS}

From the theme and content of this article the following lessons can be learned and conclusions made:

- Human activity is organized in terms of various categories of spatial systems inclusive of urban form as nodes with different ranking fulfilling specific functions that are interdependent in socio-economic space. The organization and location in space is well researched and described in supporting literature on transportation and urban form. Human activities in space are complex with high levels of need for integration and alignment based on its functions, role and ranking within spatial systems.

- Transportation integration of urban form (nodal areas) within spatial systems includes inter- and intra-movements of people, goods and services. The problem of distance between spatial systems is overcome (at a price) through application of transportation technology for improved travelling and service delivery times (accessibility) driven by the objective for improved integration. In this introduction of new transportation, technologies serve as an incentive within highly complex and dynamic spatial systems to optimize demand and potential through a range of modal choices.

- Transportation and urban form integration is characterized by different challenges, problems inter alia in migration, urban sprawl, congestion, need for infrastructure upgrading and socio-economic realities and impacts such as environmental degradation. Spatial systems consist of distinct geographical areas (refer to the theories for urban areas and regions) consisting of identifiable geographical regions inclusive of urban nodes, transi- 
tional zones and rural components integrated through systems/networks of transportation and communication.

- Development and growth in spatial systems are internally and externally induced and result in higher demand for transportation and communication systems integrating such components through improved accessibility and linkages.

- Addressing these developments requires new strategic thinking, planning, integration and coordination amongst all professions involved in planning, land use, systems development, service delivery, infrastructure development, logistics and application of technology. Politicians, communities and professions require trans-disciplinary thinkers and a commitment to promote sustainability and resilience in spatial systems that are becoming spatially more integrated and sensitive in terms of environmental, socio-economic and human impacts.

- This ever-changing and dynamic spatial systems need to be planned and integrated through the application of simulation and modelling techniques by all professionals, disciplines and practitioners involved in planning, development and management. The resulting complexities can no longer be dealt with in isolation through traditional planning methodologies and approaches. System integration by application of new technology to support choices and decision making needs to be implemented. Rethinking the role of strategic planning through lateral and trans-disciplinary planning techniques amongst professional disciplines will promote effective and efficient functionality between spatial systems in enhancing integration.

- The purpose of this article is to enhance transportation and urban form integration based on the need for disciplines to apply trans-disciplinary planning, creating the opportunity through modelling as a tool to enhance such integration and for improved decision making. This article is not an endeavour to develop a specific model as the development thereof is very complex, diverse and dynamic. The article clearly illustrates that the debate on the application and use of modelling needs to be addressed due to complexities in the development of spatial systems as to enhance urban sustainability and resilience.

\section{REFERENCES}

[1] Schoeman, C.B., Transformation within transportation planning in South Africa: implications for the implementation of the National Transport Master Plan (NATMAP) of 2011. WIT Transactions on the Built Environment, 130, pp. 3-26, 2013, ISSN 17433509.

[2] Schoeman, C.B., Intermodal transportation perspectives in South Africa: a case study of its application to the Gauteng Province and lessons learned from other metropolitan areas. WIT Transactions on the Built Environment, 138, pp. 3-15, 2014, ISSN 17433509.

[3] Schoeman, C.B., Transportation planning within the Gauteng Province of South Africa: an overview of instruments on strategic planning between 1970 and 2014. WIT Transactions on the Built Environment, 146, pp. 119-130, 2015, ISSN 17433509.

[4] Schoeman, C.B. (Ed.). Land Use Management and Transportation Planning. WIT Press: Southampton, UK, 2015.

[5] Dawkins, C.J., Regional development theory: Conceptual foundations, classic works, and recent developments. Journal of Planning Literature, 18(2), pp. 131-172, 2003.

[6] Warner S.B. \& Whittemore A. American Urban Form: A Representative History. MIT Press: Cambridge, MA, 2012.

[7] Larkham, P.J., The study of urban form in Great Britain. Urban Morphology, 10(2), pp. 117-141, 2006.

[8] Donovan, S., Cagney, M.R. \& Munro, I., Impact of urban form on transport and economic outcomes. NZ Transport Agency Research Report 513. Wellington, New Zealand, 2013. 
[9] Kenworthy, J. \& Hu, G., Transport and urban form in Chinese cities: An international comparative and policy perspective with implications for sustainable urban transport in China. DISP 151. China, 2002.

[10] Muller, P.O., Transportation and urban form-stages in the spatial evolution of the American metropolis. The Geography of Urban Transportation. eds. S. Hanson \& G. Guiliano, Guildford Publications, Inc.: New York, 2004.

[11] Rodrique, J.-P., The Geography of Transport Systems, 3rd ed., Routledge: New York, 2013.

[12] OECD International Conference Proceedings. Guidelines for Sustainable Transportation. Vancouver, Canada, 1996.

[13] Banister, D. \& Lichfield, N., Key issues in transport and urban development. Transport and Urban Development, ed. David Banister. E \& F.N. Spon: London, 1995.

[14] Gist, N.P. \& Fava, S.F., Urban Society. Thomas Cromwell Co: New York, 1974.

[15] Mumford, L., The City in History: Its Origins, Its Transformations and Its Prospects. Secker and Warburg: London, 1963.

[16] Keeble, L., Principles and Practice of Town and Country Planning. The Estates Gazette Limited: London, 1968.

[17] Friedmann, J., Regional Development Policy - A Case Study of Venezuela. MIT Press: Cambridge, MA, 1966.

[18] Friedmann, J.A., General theory of polarized development. Growth Centres in Regional Economic Development, ed. Hansen, The Free Press: New York, 1972.

[19] Murphy, R.E., The American City: An Urban Geography. McGraw-Hill Book Company: New York, 1966.

[20] Carter, H., The Study of Urban Geography. Edward Arnold Publishers Ltd: London, 1973.

[21] Murphy, R.E., The American City: An Urban Geography. McGraw-Hill, Inc: New York, 1974.

[22] Kaplan, D., Wheeler, J. \& Holloway, S., Urban Geography, 2nd ed., John Wiley and Sons, Inc.: Hoboken, 2009.

[23] Bertraud, A., The spatial organization of cities: Deliberate outcome or unforeseen consequence? Available at duatreb@msn.com or http://alain-bertaud.com, 2004 (accessed 15 November 2015).

[24] Aurousseau, M., The distribution of population - A constructive problem. Geographical Review, XI, 1921.

[25] Duncan, O.D., Scott, W.R., Lieberson, S., Duncan, B. \& Winsborough, H.H., Metropolitis and Region. Published for Resources for the Future, Inc. John Hopkins Press: Baltimore, 1960.

[26] Nijkamp, P. \& Abreu, M., Regional Development Theory. Publication Series Research Memoranda 0029, VU University Amsterdam, Faculty of Economics, 2009.

[27] Szajnowska-Wysocka, A., Theories of regional and local development - abridged review. Bulletin of Geography. Socio-economic Series No.12, 2009, pp. 75-90.

[28] Capello, R., Location, regional growth and local development theories. AESTIMUM, 58. Firenze University Press, 2011.

[29] Albrecht, L., Healey, P. \& Kunzman, R., Strategic planning and regional governance in Europe. APA Journal, 69(2), pp. 113-129, 2003.

[30] Albrecht, L., Strategic (spatial) planning reexamined. Environmental and Planning B; Planning and Design, 31, pp. 743-758, 2004. 
[31] Oleson, K., The neoliberalisation of strategic spatial planning. Planning Theory, 13(3), pp. 288-303, 2014.

[32] Pinson, G., Urban and regional planning. Encyclopedia of Governance. Vol. 2, ed. Mark Bevir, University Jean Monnet of Saint-Etienne: France, 2007.

[33] Litman, T., Planning principles and practices. Transport Policy Institute (www.vtpi.org/ Info@vtpi.org) Victoria. Canada, 2010.

[34] Schoeman, C.B., Urban and regional planning and the interface with environmental management and transportation planning. Inaugural Address. Nr. 238, Scientific Contributions. North West University, Potchefstroom Campus, 2010.

[35] Elmqvist, T., What is the difference between sustainability and resilience and how does it matter for cities? Lecture delivered at the NWU (Potchefstroom Campus). Stockholm Resiekience Centre, Stockholm University, Sweden.

[36] Geerlings, H. \& Stead, D., The integration of land-use planning, transport and environment in European policy and research. Transport Policy, 10(3), pp. 187-196, 2003. DOI: 10.1016/S0967-070X(03)00020-9.

[37] Stead, D., Geerlings, H. \& Meijers, E., Integrated land-use planning and environmental policy: An international comparison, Vol. 1. OTB Research Institute for the Built Environment. Delft University for Technology, Rotterdam, 2003.

[38] Stead, D. \& Meijers, E., Policy integration in practice: some experiences of integrating transport, land-use planning and environmental policies in local government. Berlin Conference on the Human Dimensions of Global Environmental Change: Greening of Policies-Linkages and Policy Integration, Conference Proceedings, 2004.

[39] United Nations Environment Programme (UNEP), Integrating the environment in urban planning and management - key principles and approaches for cities in the $21 \mathrm{st}$ century. Nairobi, Kenya, 2013.

[40] Iacono, M., Levinson, D. \& EL-Geneidy, A., Models of transportation and land use change: A guide to the territory. Journal of Planning Literature, 22(4), pp. 323-340, 2008.

[41] Sivakumar, A., Modelling Transport: A Synthesis of Transport Modelling Methodologies. Imperial College: London, 2007. DOI: 10.1177/0885412207314010.

[42] Giuliano, G., New directions for understanding transportation and land use. Environment and Planning A, 21, pp. 145-159, 1989. DOI: 10.1068/a210145.

[43] Eggenberger, M. \& Partiario, R., Development of a framework to assist the integration of environmental, social and economic issues in spatial planning. Impact Assessment and Project Appraisal, 18(3), pp. 201-207, 2000.

[44] Goodstadt, V. \& Partidaro, M.R., Spatial Planning and Environmental Assessments. Department of Environmental Affairs. Part III: The Practice, TEEB for local and regional decision makers. https://www.environment.gov.za/.../economicsof_ecosystems_ spatialplanning_enviroassessment.pdf. pp. 105-123, 2010 (accessed 19 January 2016).

[45] Davis, M., Green infrastructure in-depth case analysis: Theme 7: Mapping for Planning. IEEP, Ecologic, GHK, TAU, University of Antwerp, VITO, 2010.

[46] Waddell, P., Integrated land use and transportation planning and modelling: Addressing the challenges in research and practice. Transport Reviews, 31(2), pp. 209-229, 2011. DOI: $10.1080 / 01441647.2010 .525671$.

[47] Waddell, P., Modelling urban development for land use, transportation, and environmental planning. Journal of the American Planning Association, 68930, pp. 297-314, 2002. DOI: $10.1080 / 01944360208976274$. 